\title{
Interview
}

\section{An interview with Dr. Suresh Canagarajah on academic mobility, language and literacy}

\author{
Rumana Hossain \\ University of Leeds \\ (Text received 7 July 2017; accepted 7 July 2017) \\ DOI: https://doi.org/10.5565/rev/jt13.757
}

Dr. Suresh Canagarajah is Edwin Erle Sparks Professor of Applied Linguistics, English and Asian Studies at Pennsylvania State University, USA. He has a PhD in Applied Linguistics from the University of Texas at Austin and an MA in English from Bowling Green State University, Ohio. His recent publication, Translingual Practice, won AAAL's inaugural best book award, in addition to the BAAL book prize and the MLA Shaughnessy Award. He is a former President of AAAL, was the editor of TESOL Quarterly from 2005 to 2009, and editor and author of several books and over 50 journal articles and book chapters. Throughout his academic career, Dr. Canagarajah has advocated for practices that empower language learners at all levels and make use of the inherent creativity multilinguals bring to their acquisition of language and literacy competence. In his recent work, he has considered the new forms of globalization and mobility that lead to fluid discursive and linguistic practices between communities.

\section{Interview (June, 2017)}

Interviewer: Hello Suresh. Could you please share with us your response to the accusation that mobility is a newly fashionable term in academia without significant implications for scholarship?

Suresh Canagarajah: I think it is a fair criticism because lots of people talk nowadays about the "mobility turn". People are sick and tired of all kinds of "turns". For example, people talk about the "linguistic turn", the "spatial turn" - all these things are trends in academia. So it has to be agreed that mobility is not something new, mobility has always been there. It is part of human development from ancient history. People have always been moving, people have always felt connected. May be the only thing to be said about modern time is there is technology. And a lot of things related to recent technological developments, like digital technology and travel, which 
make mobility easier. And I think it is David Harvey, the geographer, who talked of compression of space-time difference. Somebody has put it rather humorously. They say "geography is history", meaning place has been conquered by time. Place difference does not make any sense anymore. It's history! They mean that spatial differences do not matter any more. You can be anywhere at the same time. So, isn't that interesting? Geography is history. They claim that there is no barrier to mobility and to what we can do. We can be instantaneously in multiple places, for example.

So some people might say, along those lines, along with the idea that geography is history, that mobility is a new phenomenon. That because of the technological difference, etcetera, mobility has intensified - which is acceptable. But I think I would push back against the notion that mobility is an academic trend, or new trend that has more significance. What I think is that although mobility is ancient, and mobility has always been there in many different periods, we have not been addressing mobility properly. For example, in linguistics, or even sociology or cultural studies, we have made all activities into structures. You know, in linguistics, every language is treated as having its own structure. And so what structure means is that we have made activities static. So I don't know whether they use this term in your field of education, in some fields they call the study of particular society, language or culture as a synchronic study. And synchronic means, you make it stand still in time. Diachronic is historical study. The founding of modern linguistics is based on synchronic study. Making language stand still in time as a structure is the proper form of study. Because you know, of course, it is easy to study language as a structure that is not moving. I think that trend has been there in a lot of disciplines, where we have been studying different social phenomena as a structure. I think mobility becoming an important turn in academic fields makes us question the whole development of academic fields studying static structures. So, although it is a fashionable turn, I think mobility is an important development. We have been able to address things that we have not been able to address in the past. One example, as I mentioned earlier, is moving away from static, structured ways of looking at language or communication or society to looking at all of these as mobile, as moving in space and time. So, for that reason, although it is questionable, I think it is an important development because people have not been talking about mobility as an important phenomenon in their lives. 
Interviewer: Thank you Suresh. What difference does mobility make to doing research on language and literacy, then?

Suresh Canagarajah: We have been thinking about languages as each having a separate structure - like English is separate from German, German is separate from Italian, That all of them have their own structure. But mobility reminds us that before these structures are formed, all languages are mobile. One of my friends, Jan Blommaert, a Belgian sociolinguist, puts it this way: he says we have to think of languages as mobile resources. Languages are words that are moving everywhere. So, for example, English has three words from my native language, Tamil, and people who would listen to my accent would say, "You are not a native speaker of the language of English, you don't know English". They forget that they have taken over my words in their language and are treating them as part of their language. Another way of putting it is: all languages have mix of words which they have borrowed from many cultures, many communities, many languages. But scholars have not been addressing language as a mobile resource. We have always been addressing language as a static, grammatical structure. So it is important for linguistics now to think about how languages are made up of mobile resources. We have appropriated words and grammatical structures from multiple languages, cultures, and communities - and that is true for all languages.

Or, another way to put it is: all languages are characterized by contact between languages, between people, between cultures. But when we look at them as separately structured, we ignore all these histories of contact. So we are now trying to address what it means to look at language interactions as made up of mobile resources. Just to give you one example: when I am speaking in English and I use a Bengali word with you, some native speakers might say that this is not English. What I would tell them is English already has many words that it has borrowed from so many cultures and this is an ongoing process; that languages are interacting with multiple languages, appropriating a lot of resources from other languages. And what's wrong with it when two people talk, and they mix English with Bengali or Tamil? That is how languages are made. So you can see the problem. Purists would say you should keep English separate, almost as if English is a distinct, pure language. But I would say: because of mobility, English has the traces of its mobile history with many languages. And that is ongoing.

So you see it makes a big difference in linguistics to think about language mixing and 
language switching as a natural process rather than an unnatural process. In literacy, it is the same thing. We have taken texts as an isolated product, one text separated from other texts. But thinking about mobility in literacy would make us think how texts travel through time. Take for example Bhagavad Geeta. There is a lot of history and a lot of time difference in how Bhagavad Geeta as a text evolved. Some of it might have evolved in the oral kind of literature, people told these stories orally or narrated them and then it became a text. And when a person in the United States reads Bhagavad Geeta, would they understand it in the same way as somebody in India understands it? Earlier, people would say all texts mean the same everywhere. That is the tradition of autonomous literacy; that is, keep the text separate, or keep the text objective, separate it from history, separate it from culture, the text can speak for itself in any time, all time. So this is an objective way of looking at the text and saying this text means this meaning or this theme for all time, for all people. But now we are beginning to question that. I say text travels and they make many different meanings for many people. This does not mean relativism, such as I understand Bhagavad Geeta differently from you, and all meanings are fine. But it actually calls for more "negotiation". That is the word I use for my publication.

Negotiation means how do I engage with the history of this text from my own positioning? You know, from where I come from. I come from Sri Lanka, from the Tamil community, or if I am living in the United States, I am a bilingual who speaks different languages. How does my difference make me look at Bhagavad Geeta or read Bhagavad Geeta differently? How can I engage with the history or the many interpretations Bhagavad Geeta brings from over time? Actually it calls for more engagement, more responsibility. So mobility in literacy brings into focus the production, reception and circulation of texts. It reminds us not to take the text as a finished product, but that it has been written by someone over time, that it has been received by people over time differently in different places. So what has happened in the course of this textual travel? This poses new questions for literacy, not to take texts as a static finished product as in autonomous literacy, but to take texts as mobile, that are travelling through time and therefore calling for more responsible interpretations.

Interviewer: Thank you very much, Suresh. That was very informative and very interesting. Does mobility create new challenges for English language teaching? 
Suresh Canagarajah: Yes. Already the examples I gave for the previous question suggest a lot of new questions for linguistics and for literacy. But there is a new problem for English language teaching. Earlier when we taught English in our countries to second language speakers or multilingual speakers, we said we have to teach English in a way that our students can talk to people in Britain or talk to people in the United States. So native speaker proficiency was the norm. These are the people who owned the language and therefore we said that's our target. Now, with mobility, we are using English not only with the native speakers but also with so many other multilingual people. So when I speak English with you, a Bengali, why bother about the native speaker norm? It does not make any sense to us. We bring a very different background with English.

The new problem now is: we have to accept diversity and unpredictability in communication. I do not know with whom I am going to use English at any given time. Perhaps it is not going to be an Anglo person from the United States. It can be anyone from anywhere in the world because of globalization, because of mobility, because of diversity. So my big question is: how do I teach English for unpredictability? And that is a big question because teachers want convenience in their teaching. It is easy if there is one structure, one norm. They would love to say: "This is the right way to use English, and if you learn it in this way you are going to be fine". And what I am saying is, that is a very wrong approach because this student is going to meet people who come with different norms. So if a teacher teaches only one norm, maybe the native speaker norm, it is not going to be enough anymore. Because you do not know with whom you are going to use that language. People tend to bring in their own norms like: Indian English, Bengali English, Pakistani English, American English, Nigerian English.

So my question is: how do we teach English for unpredictability? So that is taking me away from norms, such as saying that this is correct English. I am not worried nowadays about what norms to use in my teaching or communicating, but how to use English with people who bring different norms? There is a shift from what to how, right? What I mean by "how" is: when I meet a person from a different background who speaks differently, how can I communicate in a way that I make sense to them and what can they do to make sense to me? So the question now is, we can't assume that everybody knows this grammar or the way I pronounce something in sentences. I am saying we have to consider the how of talking. That is: you bring a different accent, you bring different words, I bring different words and grammar; how can I communicate 
in a way that I can make sense to you and you make sense to me? So this is actually making a shift from grammar to strategies, or norms to practices. So I am actually using my time with my students to teach them negotiation strategies.

A lot of people say multilingual people think on their feet, meaning that as they talk to each other, they are figuring each other's norms. Now, in schools we don't teach students' to think on their feet. We tell them: "here is the grammar, memorize it, master it and you should be fine". So they become impatient with lot of other migrant speakers. That is because they think: "hey, I learned the grammar in school, my teacher taught me and told me this is the correct way, and if you are not speaking it that way then it is your problem". If you assume that there would be unpredictability in all conversations, then English language will have to change. We can't depend on one grammar. We might have to move from grammar to practices, or from grammar to strategies, and think of what kind of strategies may help us renegotiate norms or co-construct new norms when we talk in a context of diversity.

Interviewer: Thank you, Suresh. Does the glorification of mobility in this neoliberal era make the demands of indigenous and postcolonial communities for their own sovereign land sound old fashioned or backward?

Suresh Canagarajah: Yes. I guess in the neoliberal dispensation people talk about flexibility as the norm. We should be flexible to move anywhere, to move to other countries, other places for jobs. I guess the logic is that whatever the market dictates, whatever is profitable or marketable, we should do that. We should be able to leave a country, go to a new place, because that is where your production would be cheaper or marketing would be more profitable. So flexibility is treated as an important phenomenon in neoliberalism and therefore mobility, crossing borders for work, education, for products, for ideas is considered more profitable. But at the same time, being placed is also universal and ancient. People like homes, a space that they can call their own. As I mentioned earlier, mobility has been there since ancient times, but placement has also been there since ancient times. Now we need to figure out how to bring these two together, not to think of them as dichotomies or opposites.

Actually, in some circles they have a bad word for valuing mobility without being placed. In the study of cosmopolitanism, they have a nice word: "rooted cosmopolitanism". And what 
that word means is although you are a global citizen, you also have a strong acceptance of where you belong, you also have a pride in where you come from. On the other hand, if you are not a rooted cosmopolitan you can be a wishy-washy, airy-fairy person. You pretend like "I do not belong anywhere" or "I belong to the whole world", without any identity or commitment. People say that is impossible: you cannot belong everywhere, you have to belong somewhere. If you say you do not belong anywhere, you might not have a strong sense of identity and acceptance of who you are. On the reverse of rooted cosmopolitanism, therefore, there is a term 'elite cosmopolitanism'. There are people who are flying all the time, they are so rich, they are in airport lounges drinking, eating all kinds of strange foods. They do not have the sense of belonging and a lot of people feel that is possible for rich people. People with rooted cosmopolitanism understand where they come from, but also have a global point of view and a global acceptance of diversity. Those people might be better situated to make better contributions to society.

So, what I am trying to say is: thinking of mobility without sense of place is first of all not possible, there is always a sense of place. Also, it may not be good for people to think of themselves as not belonging anywhere. So I would say that even in the context of mobility and neoliberalism, I can appreciate how some communities feel that they have a right to their own lands, they have a strong desire for home - for place, to being placed. The only qualification I will make is that the place that you claim should not be treated as homogeneous or pure, because many people have lived in this place for centuries before, and still live there. Sometimes when we think about communities, we think of them as homogeneous and we close our eyes towards lot of diversity. Take for example Bangladesh. There are a lot of Christians in Bangladesh. If some people define Bangladesh as an Islamic community, belonging to the Islamic Bengali community, they might ignore other people who are Bengali but different.

So people do make claims for their land, which is an important thing. But they have to just remember: there is a lot of diversity even in the places they make claims for. The other thing is that their places have traces, evidence of mobility - meaning that other people have lived there before, they have left their marks on these lands before. Say, even in Bangladesh, the fact that it is a very bilingual country shows the evidence of colonization of British there. And so if it is possible for indigenous communities to make a claim for their land, which is totally acceptable, they must also keep their eyes open to diversity and mobility. We are still open to influences 
from mobility even when we are not moving. There are other things which are moving, like ideas, media, interactions with other communities for economy and politics. I think it might be possible to keep both things together. To be placed, to be proud of your place which you call home, but also be open to mobility.

Interviewer: Right, just one last question. I am also working on academic mobility, especially on scholars returning to Bangladesh after western training/education. What do you think could the prospects and challenges be for these scholars?

Suresh Canagarajah: A couple of things we need to consider, like why the returning scholars might not be contributing locally. Sometimes the issue is that the local scholars do not like the returning scholars, as they bring in new ideas, new knowledge. There is a power struggle, so to speak, where the local scholars feel they should hold on to their local status, their hierarchy. I experienced that when I went to Sri Lanka after my PhD. I was young, had just received my PhD. But some of the senior scholars in my university wanted me to be very quiet, and not to do anything new. Part of the fear was that they might not know the things that I had studied abroad. You feel sorry for them, sympathize with them, as sometimes they do not have access to all that information, the new books, the new research. So they feel a little insecure. That is why they want me to be quiet. That is one problem from the point of view of local scholars.

But there is also a problem from the returnee's point of view. Sometimes we do not know how to make the connection between the new knowledge and the traditions back home. The returnees have a condescending attitude towards the local educational enterprise. They think these people are so old fashioned, they are so traditional, they are so superstitious. For example, in Bangladesh, I can imagine there might be educational institutions which are religious, which are Islamic. Therefore they would not be consistent with the secular knowledge that we bring from abroad. There can be a tension.

So there can be problems on both sides. Here again, the word I used before, "negotiations strategy", might be important. That is, we cannot be one-sided. We need to figure out how to adopt a balanced approach to the local. So what I would try to do if I go to Sri Lanka is: first of all, acknowledge that there are also good things to traditional systems and local approaches. In my context, Sri Lanka, what was popular was very personal and narrative forms of knowledge, 
where people would not care to be objective, scientific, or impartial in their approach. They would be personal. They would tell stories. However, there is an appreciation of some of these approaches in the West. There is a reaction against empiricism. People are saying: "we are pretending to be a machine or a robot who does not have any feelings". We are people with values and assumptions about what is good knowledge. So, what I found was there is something good about the local way of approaching knowledge, which is narrative and personal. But how can we also make it a little more disciplined and more responsible? Because, sometimes, this local knowledge and personal knowledge in our local universities end up in fights, rumors, fisticuffs, people fighting with each other. What I tell them is: it is ok to construct knowledge from your personal experience, but can we adopt a position where we act responsibly or can we say things that others might agree upon? Or can I see how my own experience relates to other peoples' experience? Or acknowledge that just as I have values or assumptions about how things work, other people also have their values and assumptions. So, that calls for a negotiation, right? It has to be a two-way approach; one has to try to understand the local traditions and approaches, and then also be critical of the empirical, secular traditions they are bringing from the West. And also how to introduce the good things they are bringing locally in an understanding way.

So, that is what I tried to do when I returned to Sri Lanka, and in some cases it worked. People appreciated it and said: "You are translating things that you have in a way that we can understand and appreciate". And here is another problem when we introduce something as new, fashionable and superior in our country. There is immediately a reaction. People do not like that because they think you are trying to make them look inferior. On the other hand, if you present it as: "See, what we are doing locally, one tradition in the Western academy would agree with you, like the personal and the narrative" - then there is a nice opening to talk further. Then you can say: "We also need to be careful and disciplined". You can introduce them to narrative research, or auto-ethnography in the West. Then they will say: "Oh, I see this is how they talk about personal experience in the West". So, eventually, out of this, I think there might evolve a hybrid academic culture which is good for everybody - where the local scholars will feel we can appropriate the new knowledge according to our history and traditions, but also evolve, develop some new ways of looking at it that are a continuation of what we are doing here. And the returning scholar can also learn if they are heavily influenced by the West. They can see how to connect their new knowledge in relation to the local practices and they can also evolve. 
I think part of mobility is also hybridity, in the sense that there is always going to be some mixing. Which brings me back to the first question about language contact, language mixing. And the same thing happens in knowledge. In a talk I gave in University of London last year, when I was a visiting scholar there, I called it "creolizing the Humanities". And what it meant is people think of Creole language as a mixed language. Long time back they did not even think of it as a language, they thought it was like a polluted language and a functional language of uneducated people. But now creolization is becoming a key word for all disciplines. And I was actually drawing from creole practices in linguistics to say how, in academic work, we can also be creole scholars. In the example I gave you of the local and the global in terms of your returning scholars, there is creolization of knowledge. But creolization can also mean interdisciplinarity, how we relate our knowledge in one field to the knowledge in other fields. Or it can also mean how we can relate our knowledge of one geographical location, say England, to knowledge of another geographical location, say Bangladesh or China or India. So developing knowledge today is kind of multi-sited and it draws from multiple sources, whereas in the past the enlightenment tradition looked at knowledge as belonging to one community. Europe had all the knowledge, everybody else does not know what they are doing, right? So if you think of your academic world also as a form of creolization that rises out of mobility, then it is possible that returning scholars will engage better with local educational practices, intellectual traditions, and develop something new and constructive.

Interviewer: Thank you very much, Suresh.

\section{References}

Blommaert, J. (2011). Repertoires revisited: 'Knowing language' in superdiversity. Working Papers in Urban Language \& Literacies, WP67. Retrieved from http://www.kcl.ac.uk/sspp/departments/education/research/ResearchCentres/ldc/publications/workingpapers/the-papers/67.pdf

Canagarajah, S. (2017). The Routledge handbook of migration and language. New York: Taylor and Francis. https://doi.org/10.4324/9781315754512 
Author information:

Rumana Hossain is a PhD researcher at the University of Leeds, UK. She is currently researching the experience of Bangladeshi academics on return from study abroad for her PhD. She has also done an MA in TESOL from the same university. Rumana has been in the field of Education for the past fifteen years and wishes to excel in the field of Education and Teacher Development through research-oriented studies and student-focused teaching. Her publications cover a wide range of areas, including language teaching and learning, sociolinguistics and teacher development.

Email: ed13rh@leeds.ac.uk; rumanarh@gmail.com

To cite this article:

Hossain, R. (2017). An interview with Dr. Suresh Canagarajah on academic mobility, language and literacy. Bellaterra Journal of Teaching \& Learning Language \& Literature, 10(4), 93-103. DOI: https://doi.org/10.5565/rev/jt13.757 